\title{
DISAPPEARING MANGROVES: The Epistemic Politics of Climate Adaptation in Guyana
}

\author{
SARAH E. VAUGHN \\ Yale University \\ University of California, Berkeley \\ (D) http: / / orcid.org/0000-0001-7127-0575
}

"See! Just ruined," shouted Carmichael as he pointed into the distance where mangrove trees once stood. ${ }^{1}$ Carmichael, a state-sponsored civil engineer, was leading me on a walk along the seawall of Guyana's Atlantic coast. He was gathering information for a newly implemented climate-adaptation policy called the Guyana Mangrove Restoration Project (GMRP). The forest's low-hanging branches and its spongiform earth made the walk all the more laborious. As we clumsily maneuvered around trees, Carmichael explained, "Those mangroves are gone now. . . . We don't know why those mangroves uprooted.” More importantly, he noted, "We can't just replace them." It was not easy to change the calculus of the forest, even a little bit. For Carmichael, climate-adaptation policies like the GMRP are opportune. But they still might not get him anything more than a hold on the status quo - that the forest is a rather unstable place.

In 2010 the Guyanese government announced the launch of the GMRP. As a response to the threat of sea-level rise, the GMRP looks to mangroves for storm protection. The program is partially funded by the European Union's Global Climate Change Alliance, which complements UN climate treaties by supporting national-level research about climate adaptation. For engineers more familiar with seawalls than mangroves as defense against the sea, the GMRP entails a particularly broad-based research program into mangrove ecosystems. It focuses on exploring 
how and why processes of erosion impinge on forests. These research questions have put engineers in unorthodox partnerships with other technoscientific experts, including geoscientists analyzing mudbanks, environmental consultants cultivating trees, and beekeepers developing apiaries. This is not to say that their combined efforts always prove effective - they are, in fact, often thwarted by a variety of things like waves, mud, and debris. In Guyana's forests, climate adaptation requires expertise that can reconcile humans' and nonhumans' entangled and increasingly insecure futures.

The factors that contribute to mangroves' vulnerability inform the kinds of practices GMRP participants use to observe, measure, and analyze them. The participants' time in forests forces them to recognize that climate adaptation is not solely dependent on their well-intentioned efforts. Through these encounters, their understandings of mangroves transform, and what was once familiar terrain suddenly appears strange. In this article I examine the ways in which climate adaptation holds purchase and sway among GMRP participants, as well as the role mangroves play in constituting their relationships with each other. As research objects, mangroves are not only forms of evidence but also tools that guide expert action and distinctions in day-to-day labor. Thus, what follows is an ethnography of how epistemic politics shape climate adaptation and its enactments of expertise.

During the initial phases of research, GMRP participants produced a report describing Guyana as a difficult place for mangrove research. In the face of a call for improved communication between engineering and agricultural agencies, the report highlighted the complex dynamics of erosion shaping the coastal plain. It built on a model that engineers have long used to explain mangroves' vulnerability: that of mudbank migration. Mudbanks are formed by the mixing of silt and clay in the Amazon and Orinoco Rivers. They can vary in length from a few hundred feet to three miles. As they migrate from rivers along the shorelines of northern Brazil, the Guianas, and Venezuela, they dampen waves and provide sediment for mangroves to take root. Yet the areas between mudbanks are prone to erosion and susceptible to mangrove loss.

The fact that mudbanks will eventually migrate meant that GMRP participants had to devise a plan to manage and restore forests. To facilitate planning, geoscientists created a model detailing mudbank and mangrove interactions. Engineers focused on instituting a program in forest mapping. Meanwhile, environmental consultants and beekeepers concentrated on administering forest reserves. All contributed to constituting a field of expertise in mangrove disappearance. Despite their varying terminologies, all were adapting to climate change. 


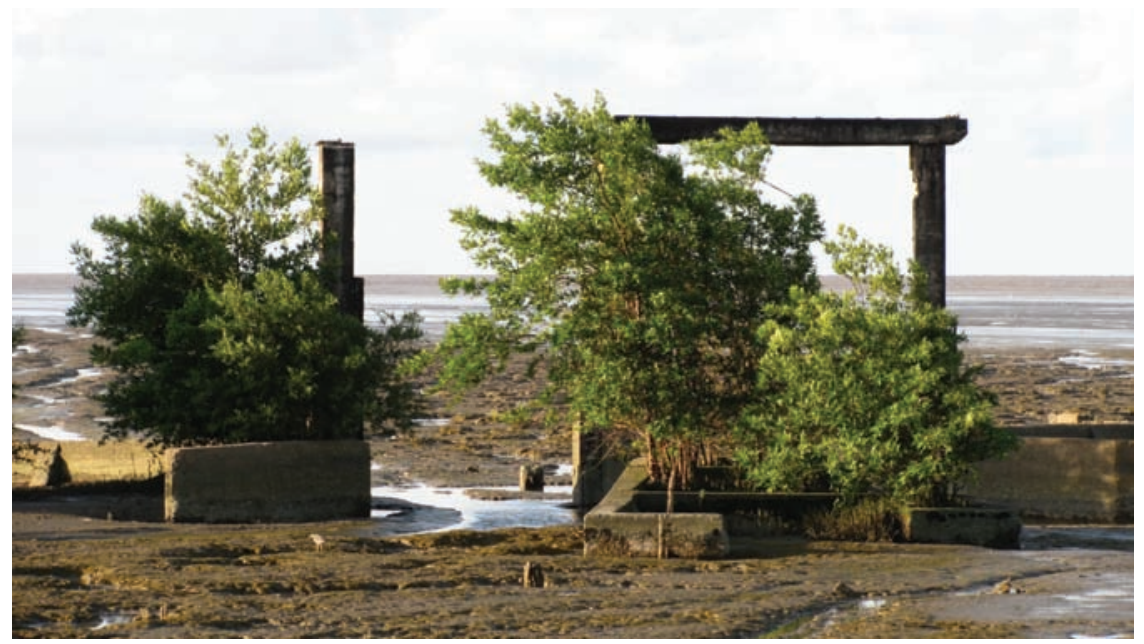

Figure 1. Mangroves huddled around derelict sea defenses at low tide. Photo by Sarah E. Vaughn.

Climate adaptation unfolds in asymmetrical ways, not only among GMRP participants but also within forests. While GMRP participants may rely on a variety of practices to restore mangroves, the mangroves themselves do not always respond as helpful companions. They can distract GMRP participants or slow down their work, creating moments that sometimes lead to new insights and, in other cases, to dead ends. In this article, I offer a close analysis of these encounters and the concerns they provoke among experts about the viability of climate adaptation as a policy.

First, I tell the story of the previous crisis in sea defense that brought about a paradigm shift in modeling under the GMRP and its climate-adaptation efforts. I suggest that climate adaptation simultaneously depends on scientific accounts of vulnerable environments and experts learning to recognize their limited capacities to manage them. This background is followed by an analysis of engineers' forestmapping activities, which details the relationship between expertise and enumeration. I then explain how environmental consultants' planting activities help them to reconcile doubts about mangroves as sea defense. I explore the ways that this doubt materializes in the bodies of other kinds of living things, particularly through the work of beekeepers. Finally, the conclusion offers a broader discussion about how this case of climatological expertise can contribute to anthropological discussions about expertise and performativity. 
In their efforts to think and act with mangroves, GMRP participants constantly test expert practices in sea defense. Their encounters with mangroves tie together human and nonhuman potentialities, research programs, and the localized ecologies to which they become obligated. The GMRP offers just one example of climate adaptation in action, and of experts' imperfect aspirations to relate nature to technology. Impermanent and wondrous, mangroves urge us to think more creatively about vulnerability to climate change and the kinds of practices that inspire knowledge about it.

\section{STORIES WE TELL}

This article joins conversations in the anthropology of expertise on climate adaptation (Orlove 2009; Barnes 2016; Crate and Nuttall 2016; Whitington 2016) by examining the ways in which experts become aware that climate change threatens sea defense. I analyze a variety of forms of expertise-competence in an activity that requires a practical skill set (Boyer 2008; Carr 2010) - as they are enacted in and across vulnerable environments. At the same time, I emphasize the unpredictable course of such expertise, as it extends beyond the ecologically knowable or measured impacts of climate change.

The idea that mangroves can be maintained as a primary form of sea defense is a recent one in Guyana. It is rooted in certain qualities of Guyana's coastal plain, which is below sea level, subject to biannual rainy seasons, and historically resistant to human efforts to hold back flood waters. More than 90 percent of Guyana's population lives on the coastal plain, where agriculture has long been the dominant industry. Beginning in the late seventeenth century, Dutch colonists imported slaves from Africa, while British colonists later brought in more slaves and indentured laborers from India, Portugal, and China to cultivate sugar. Since, flood management has been tied to sugar plantations' elaborate canal and seadefense grid. ${ }^{2}$ This grid snakes between farms, city promenades, rivers, and shopping centers, blurring distinctions between rural and urban flood management. In the capital city, Georgetown, fifty miles of drainage canals support roughly three hundred thousand people. But tons of debris and garbage fill them daily, compromising engineers' efforts to drain water. Part of the problem with floods in Guyana is that people have tried to outrun the coast. So, too, have the new economies in tourism and luxury real estate that infringe on mangrove forests. Yet the architecture of these economies is increasingly built out of concrete instead of wood, a shift some engineers believe contributes to land sinking into the Atlantic. 
Rahul Battacharya's novel The Sly Company of People Who Care crystallizes what these coastal transformations mean for the people Battacharya $(2011,102)$ calls "water technicians," writing that "everything [they do] starts with the land." Some of these people are participants in the GMRP. Their work with mangroves is haunted by a dystopian sense of an untameable world. They envision a restorative unity with nature, but have parted with older fantasies that human technologies might guarantee sea defense. They do assume, however, that mangroves require expert interventions to survive, even when those interventions are not always aligned with clear objectives, let alone outcomes.

In recent years, mangroves have been subject to various land and protected species acts. Yet one would barely notice this fact. Guyana's coastal forests are dominated by acres of black species (Avicennia germinans), with patches of white species (Laguncularia racemosa) that compete for nutrient rich soils. While the GMRP is primarily concerned with mudbanks, its participants also worry that sea-level rise could upend this dynamic. Indeed, climate change leaves no time for humans to negotiate a "contract with nature" (Latour 2014, 6-7). These regulations provoke porous zones of inquiry about the relevance of climate-adaptation policies like the GMRP. How best to relate to mangroves? When does a mangrove tree form part of a forest or sea defense? Why and who cares about a forest under siege? In forests we witness a practical redefinition of expertise, one that shifts symbolic understandings and experiences of the world amid ecological crisis (Kohn 2015).

Mangroves demonstrate that climate change forces experts to imagine a future world without humans to manage ecological crises in the present (Chakrabarty 2009). As Julie Cruikshank (2005, 3) writes of melting glaciers, "they take action and respond to their surroundings" in ways that can challenge memories and radically reroute narratives of a given place. Mangroves, too, are part of a speculative web of not only facts but also expert figures, technologies, and coalitions that make a place imaginable (Ogden 2011). But mangroves are not solely metaphors about the specters of human agency in the Anthropocene. They also provide starting points for an analysis of the ways nonhuman matter mobilizes epistemic politics or distinctions in the day-to-day labor of knowledge production (Stoler 2008).

Scholars in the social studies and anthropology of finance have taken up this point with vigor in recent years. Their studies have illustrated that economists and other finance experts do not operate in a predetermined market environment but rather constitute markets and market activity through their expert practices 
(Callon 1998). Thus, the discipline of economics plays a pivotal role in the practical making of the market and the circulation of its discourses (Lee and LiPuma 2002; Appadurai 2015). Decisions about, say, computational programs or the use of particular variables in a formula act as performative utterances, in J. L. Austin's sense, producing effects with identifiable consequences on markets. This emphasis on the performativity of expertise counters a certain sort of essentialism, revealing how cultures of expertise seek to exert analytical authority over the world as well as other groups of experts (du Gay 2010; see also Bourdieu 1991). Donald MacKenzie's (2006) analysis of option pricing, for example, troubles the idea that mathematical formulas are self-evident snapshots of preexisting reality and suggests that they are instead an "engine" for producing that reality.

Expertise has proven no less performative within the context of climate adaptation. Their models help GMRP participants to define and monitor vulnerable forests through the construction and maintenance of grass buffers, apiaries, and fences. But, at the same time as they build these infrastructures, they learn to question the relevance of their models and the expert practices through which observations and measurements can be made. Thus modeling operations "interweave 'words' and 'actions'” (MacKenzie, Muniesa, and Siu 2007, 5), exposing GMRP participants' dependencies on mangroves to make climate adaptation a possible and sustainable practice. I suggest that these dependencies influence the ecology of human expertise and experts' collaborative efforts to create epistemic paradigms about vulnerable environments. In other words, mangroves reciprocally constitute the GMRP's operational lexicon. Though inconsistent in both form and function, they are resources for expert improvisation and contribute to the operative logics of climate adaptation.

It is no surprise then that GMRP participants find value in working and thinking with mangroves, even though they do not have full confidence in them. Mangroves have become preferred things for use in considering the limits of expertise. Specifically, they are essential to what Adriana Petryna (2015, 150) calls "blindsidedness." This is a condition in which undeniable climatological realities affect experts in such a way that they have no time to act and guarantee business as usual. Beyond modeling operations, climate adaptation depends on modes of self-reflection that find potential in the collapse, or even the erasure, of expert jurisdictions. As I detail below, GMRP participants have no problem admitting that they are less than prepared for climate change; they question if any person, species, or place is capable of adapting to its future. 


\section{EPISTEMIC JUJITSU}

Systems of mudbanks have been active in the Amazon River and Basin for the past five thousand years. Dutch and British colonial explorers' travelogues offer some of the first documented evidence of mudbank migrations (e.g., Schomburgk 1922). Colonial administrators marshaled these texts to finance agricultural labs and research in the region (Winter 1883). In turn, slaves and indentured laborers toiled on plantations, which influenced where engineers preserved mangrove forests or built seawalls (Rodney 1981, 31-33). Certainly, South America's Guianese coast has historically been a place for entangled political and knowledge projects invested in taming mud's recalcitrant form. This means that sea defense belongs within a "greater ecology of modern expertise" (Redfield 2000, 23) dedicated to reordering relations between nature and technology.

The first time engineers completed a study to investigate mudbank migration was in the early 1920s. The British colonial governor recruited foreign experts with experience in low-lying delta regions for the task (Case 1920). Gleaning insights from plantation estate records dating to the early 1800s, they identified that mangroves survive in areas with ample mudbanks. But it was unclear to them why and how some areas of the coast become more hospitable for mangroves after mudbanks migrate. In response, the governor institutionalized the "Case Method," a practice that involves engineers taking walks along the shore to monitor mudbanks and related erosion. As noted in the project report: "There is no mistake about it, our enemy is the sea. It is our business to find out what we don't know, what hitherto we have hardly begin [sic] to find out, what he [the sea] is doing . . . and whether by a kind of jujitsu we can use our own strength against him" (Case 1920, 8).

The last Case Method study was completed in 1962 by the British Guianese Ministry of Public Works, along with engineers affiliated with Delft Hydraulics Laboratories. With the aid of shore walks and eco-sounders attached to boats, the researchers conducted bathymetric surveys (underwater topography studies). The study discovered that mudbanks migrate every thirty years and that, during this migration, they cause microprocesses of erosion (Delft Hydraulics Laboratory 1962, 10). In areas where these microprocesses occurred, mangroves uprooted but regrew within three years. The researchers described these dynamics as "subject to special laws, that their consequences can be predicted and that through their magnitude indeed prevent human control" (Delft Hydraulics Laboratory 1962, unpaged preface). In light of the surveys, engineers further concentrated their efforts on building and maintaining seawalls. 
Wieber Bijker $(2007,120)$ has analyzed the (Dutch) character of the engineering that inspired the study. He describes it as oriented toward immediate strategies to "keep the water out" to prevent disaster. Predicting such events, he argues, is a "technical" issue secondary to the "professional" obligation of engineers to act at whatever cost (Bijker 2007, 121). Hence, even though the 1962 team identified the hypothetical mechanisms for predicting mangrove regeneration, engineers were never interested in turning mangroves into research objects or in considering how they might aid in the project of turning the sea's powers against itself. Their narrow focus on seawalls was further informed by the rigid administration of resources, racial-political chauvinism, and fiscal crises that characterized Guyana’s postindependence socialist era from 1974 to 1985 (Rose 2002). ${ }^{3}$ I do not mean to suggest that engineers uniformly believed in a clear association between seawalls and aspirations for modernization. ${ }^{4}$ Many simply made do with crumbling seawalls and unbalanced budgets, persevering as best they could in the face of the sea. Even with the massive debt that accompanied liberalization in the early 1990s, mangrove research was deprioritized with respect to plans for expensive seawalls. ${ }^{5}$

Priorities shifted in 2005 after unprecedented rainfall contributed to a disastrous flood. Postdisaster engineering assessments showed that the drainage system could not withstand future storms unless it underwent a comprehensive overhaul in design (Kirby, Messen, and Ogink 2006). Likewise, local media raised alarm that the next flood could come from waves overtopping seawalls. Engineering research articles of the period reinforce these concerns. Some warn that sea-level rise will contribute to extreme periods of erosion that will compromise seawalls (Ledden et al. 2009). Others highlight the "lack of understanding" (Dalrymple and Pulwarty 2006, 8) about the effects of wave intensity on mangroves. A new urgency for mangrove research emerged in the wake of the disenchantment with seawalls.

The Guyanese government responded by releasing its Low Carbon Development Strategy (LCDS), a report that notes the potential role of mangroves in sea defense (Government of Guyana 2010, 11). This strategy informs the government's Second National Communication to the United Nations Framework Convention on Climate Change, which also highlights mangrove research as an invaluable component of climate adaptation. Laying out national priorities around the various blind spots of the Copenhagen Accord, the LCDS creates a critical nexus between transnational climate negotiations and the research networks needed to sustain them. The European Union's Global Climate Change Alliance 
is one such network that caught the attention of Guyana's newly mangroveconscious government. ${ }^{6}$

Similar to that of the policy domain of public health, the potential value of climate adaptation is shaped by the research networks that emerge from previous or anticipated crises. The technopolitical careers of mangroves are implicated in these networks, but never predictably so. As research objects, mangroves have the potential to organize adaptation research and resources beyond national or site-specific vulnerabilities. More than sentinel species, they are forests that sustain the travels and propagations of diverse species assemblages (Tsing 2015). As detailed in the 2011 film Island President, mangroves are persuasive for climate adaptation in some places more than others.

The threat of sea-level rise has thus created something of a paradox for Guyanese sea defense. It places an extraordinary burden on mangroves to make visible habits of practice and coexistence, as well as their increasing discontinuities. Isabelle Stengers $(2000,159)$ argues that such visibility is central to how expertise materializes in risk-policy contexts more broadly. Experts, she explains, "have to recognize rather quickly that they are not qualified to speak of other stories, nor to follow through all its consequences the logic of the story they [wish to] advocate." So, while the threat of sea-level rise reaffirms the vulnerability of mangroves in Guyana, it has made engineers even more dependent on them as sea defense and in turn, on other kinds of expertise.

\section{MODELS FOR ADAPTATION}

The collaborative efforts of GRMP participants involved learning to treat sea defense as a complex system of animate and inanimate parts. The Ministry of Public Works recruited a French geoscientist, Nicholas, to create a model of mangrove and mudbank interactions. While engineers had created mudbank models predicting migration routes since the 1960s, GMRP participants needed something more: a model that could detail precise mangrove regeneration processes and how mangroves colonized land before, during, and after a migration. By discerning patterns in these processes, they hoped to locate fertile areas to plant trees.

Building on prior research about mudbanks in French Guiana, Nicholas's work with the GMRP extended to research teams and stations across the region. On some days Nicholas walked forests accompanied by engineers or led workshops at the ministry on modeling software and methods. At other times, he combed through a computerized archive of mudbank images downloaded from 
French and American satellites. These images afforded a regional perspective on mudbank migrations that complemented the ministry's existing records of wave data generated from bathymetric surveys. In the context of the GMRP, mangrove regeneration is targeted by planetary research infrastructures, systematic measuring practices, and graphic representations.

Nicholas's computer mouse clicked as he adjusted the resolution of mudbank images on a laptop while I interviewed him at his ministry office. I asked him what the images told him about mangroves. He dragged his cursor over black lines that marked the staggered increase and decrease in the width of the Guyanese shore. More than evidence of mudbank migration, Nicholas said that the images offered "a glimpse of mangroves" in action. This is sea defense without guarantees, a gap that makes explicit the work required to realize climate adaptation.

Nicholas modeled these dynamics with a numerical approach called the Simulating WAves Nearshore (SWAN) model. Building on the laboratory work of Johan Winterwerp and colleagues (Winterwerp et al. 2007), the SWAN model uses differential equations that assume the height and direction of dampened waves in two dimensions. The SWAN model details a particular dynamic locally called "sling-mud," a gelatinous mixture that breaks off from mudbanks as they migrate and that anchors mangrove roots both in water and on land. Nicholas incorporated parameterizations to account for sling-mud's density. With wave data from several locations, he found that the shore is shifting progressively from muddy to sandysilty conditions. Based on historical satellite images of regional mudbanks, he also assumed that sandy-silty areas would have more underdeveloped forests compared to muddy areas.

But when Nicholas and the engineers went on shore walks, they encountered muddy areas with more eroded land than the SWAN model indicated. Surprised, they watched where waves broke and fringes of mangroves dissipated. These areas had seedlings that took root in shallow crevices. Seedlings arrived there after falling from mature trees and being dispersed by waves, drawn into currents without volition and congealed with sling-mud before being carried great distances and dropped arbitrarily on the shore. Nicholas speculated that because the crevices were shallow, seedlings were not securely anchored by sling-mud. He took photographs to document their efforts. Some had limp stems while others sprouted straight into the air, seemingly determined to outmaneuver the terrain. Engineers picked at the ground around seawalls to see if those structures were impacting and contributing to the harsh conditions. Seedlings abounded, yet GMRP participants scarcely recognized them. 
After encountering erosion in other areas that the SWAN model did not detect, engineers began to treat those forests as surveillance sites. They reasoned that by monitoring insecure seedlings at these sites, they might obtain new sources of insight about tree restoration. As one engineer explained: "We [engineers] recognize moments of sedimentation. Like the other day, I was near Celina's [a resort] and saw seedlings everywhere. They weren't there a week ago when the mud there was low [eroded]. . . . We'll see what they will do." This engineer expressed a combination of wariness and curiosity about seedlings, distinguishing between the importance of sling-mud anchoring them and their relative autonomy to decide if and when to sprout. His reflections exemplify what Natasha Myers (2015, 43) calls "enchantments" with "the vegetal sensorium," or the human interest in learning to become aware of plant sentience. Thinking with plant practitioners, Myers treats plants as companions that generate interspecies relations through their movement and their physical structures. In the case of the GMRP, seedlings shaped engineers' intuitions about complex processes of sedimentation that sometimes hang together and at other times fall apart. Seedlings encouraged engineers to develop patience for sling-mud and the imperfect role it plays in the long duration of forest monitoring.

From the tiniest to the largest particles, sling-mud interacts with other kinds of things: rocks, plankton, fish, and especially sea-defense structures that create conditions for mangrove regeneration. Groynes offer another example. Built perpendicular to seawalls, groynes in Guyana are wooden structures first implemented by the colonial Dutch to reduce erosion. It is unknown, however, to what extent groynes impact sling-mud compared to other kinds of sediment such as sand and clay. As with Nicholas's attempts to calibrate sling-mud density, engineers have used tide gauges to estimate erosion near groynes. But they have found that the composition of sediment changes each day and that erosion near groynes is a process too dynamic to compute. Several engineers talked about this indeterminacy by recounting their experiences from childhood into the present day, seeing mangroves near some groynes and not others. A few proposed that the GMRP create a plan to end the ministry's dependence on groynes. Others had a less radical proposal that involved building tubes out of a flexible material that, when placed near groynes, could act as wave buffers to accommodate tree roots.

Indeed, GMRP participants were awkward intruders into the lives of mangroves. More than a paradigm shift, their work was a relational effect of geologic processes (Yusoff 2013; McLean 2011). But what kinds of worlds do their intru- 
sions create, undermine, or sustain? And why does it matter if mangroves thrive in them or not? Nicholas confronted these questions when he explained to me a disagreement he had had with an engineer over the distribution of red mangroves (Rhizophora mangle) in Guyana. He conceded: "I was suspicious of red mangroves. I've never seen them anywhere else colonizing behind black mangroves. But it's true; they are no longer right in the sea water. Many are especially near dams and canals draining freshwater. But geologically, for millennia, the coast has not been this way. They might give us a clue about what human development is doing to the shore."

Alongside engineers, Nicholas was learning to pay attention to things mangroves pay attention to, even if those things challenged his assumptions about inter- and intraspecies living. With shore-walk observations in mind, he began to change his views on mangrove regeneration. He now granted that mangrove regeneration was far more complex than he had initially thought and not primarily dependent on mudbank migration events. In consultation with the engineers, he decided that it was not necessary to refine the SWAN model to move forward with the GMRP. Instead, the participants would focus on forest mapping and tree planting to improve sea defense and their understandings of the shore.

The measured rebuffs of the SWAN model by GRMP participants show how climate-adaptation strategies can depend on nonhuman matter coming to shape new possibilities for expert action. Following Stefan Helmreich (2011, 138), mangroves "athwart theory" as entities that help experts "tack back and forth between seeing things as explanation and taking them as phenomena to be examined." This dynamic is central to decision-making in climate adaptation when models prove immediately unhelpful but experts still need to imagine and enact logistical measures. ${ }^{7}$ A view from the forests reveals that climate adaptation emerges from GMRP participants' urgent need to draw flexible distinctions between the empirical and the theoretical.

\section{ENUMERATING EXPERTISE}

Nicholas's modeling efforts forced the engineers not only to care about counting mangrove trees but also to think about how forest stocks might impinge on the shore itself. Kristen Hastrup (2013) describes similar concerns among biologists and hunters in northern Greenland who are preoccupied with climaterelated fluctuations in narwhal populations. Biologists have used aerial photography to estimate populations, while hunters estimate populations based on their encounters with prey and melting glaciers. Numbers, Hastrup suggests, mediate 
various expert understandings of nature's potential to help them relate evidence to reality.

Prior to the GMRP, engineers were not accustomed to identifying mangroves as individual living entities; rather, they saw them as unreliable wave buffers. Consequently, they aspired to create maps that could represent tree counts relative to mudbank migration routes. Their attempts at mapping required learning to pay attention to subtle changes in the space a tree occupied and what it could potentially do in that space. Mapping activities began when a ministry staff member informally interviewed engineers about their backgrounds in geographic information system (GIS) mapping techniques. He found that most had no familiarity with these techniques, so he offered some informational sessions about the importance of forest mapping to sea defense.

The engineers completed more shore walks to create a useable database for the maps. Much of the work of lower-ranked engineers involved forming groups, each responsible for monitoring (il)legal development such as boating docks, housing, and farming along the shore. Higher-ranked engineers, who had some background using remote-sensing technologies, were charged with scheduling trips to identify and keep tabs on forest growth. Eventually, when a GIS specialist was hired, the forests' coordinates would be computed and engineers' observations analyzed and transformed into maps.

As a search for a GIS specialist began, engineers attempted to identify forests that they described as robust, or areas that could possibly forego further development of sea defenses. Scouting for robust forests required them to check for characteristics that distinguished species: the length and shape of roots and the height of trees. Such distinctions mattered; while black mangroves have sturdier aerial roots, white mangroves are shorter and so are believed to be less susceptible to direct wave impact. The maps were intended, therefore, to present both a virtual stock of forests and patterns of zonation by species. In general, the engineers felt that mapping activities were shaped as much by techniques of counting as by the cataloguing of vulnerability.

Time spent in forests also informed their views about the practical import of GIS. Some noted that mapping activities forced them to change their focus and acknowledge the stress that forests placed on their daily routines. Consider, for instance, mangrove roots. Like spider tentacles clumsily treading the earth, they transform forests into mazes. Engineers had to contour their bodies to bend low, becoming fatigued as they traversed entangled roots, trunks, and branches. Shore 
walks helped engineers understand the material character of mangroves' quotidian presence as sea defense.

Engineers faced comparable difficulties when they left the forests. One engineer explained that he was ambivalent about the ministry's search for a GIS specialist. He explained, "The GMRP is back and forth. You move two steps forward and then when another [mangrove] washes away, one step back." But he noted that the ministry seemed to be reinvigorated by mangroves. With institutional support from the Global Climate Change Alliance, it sponsored publicawareness campaigns about mangroves and a regional GIS conference to share information about sea-defense standards and protocols.

This engineer's conflicted attitude parallels the differences between the GMRP and the case of Kristen Hastrup's narwhals. For Hastrup (2013, 10), "the case of narwhal counting . . . shows how both the counted and the uncounted enter into the equation that results in an iconic number on which to act." But rather than assuming nature's potential, GMRP mapping activities prompted a second look at the expertise such counting entails. For most engineers, mangroves are difficult to work with not solely because the SWAN model cannot predict their life spans but also because of their biomateriality. To this extent, GIS training is not in tension with their established epistemological frameworks or even an index of the ministry's historical struggles maintaining sea defenses. Rather, engineers acknowledge that mapping proves useful, but only because of experiential encounters with mangroves whereby expert habits, numerical assumptions, and morale are adjusted to the materiality of the forest.

The mapping done by the GMRP reverses the common narrative about climate adaptation as a strategy of defense against climate change and its destructive impacts. Instead, we see that experts interpret climate adaptation as a strategy in "modulating natural processes," so that "nature's diversity provides the 'service' of cancelling out the very risks that nature itself presents" (Braun 2014, 59). Mangroves are thus never simply objects to be enumerated; instead, they are entities that prompt certain ways of knowing.

\section{DOUBT, CULTIVATED}

As mapping continued, mangrove-planting activities commenced. While mangrove cultivation was new for Guyanese sea defense, it was not entirely unheard of in other situations of climate adaptation. Particularly in Oceania, the mass mediation of the 2004 tsunami and heightened interest in carbon markets led organizations such as the Alliance of Small Island States to sponsor tree planting 
(Lipset 2013). While many states mobilize mangrove research through a geopolitics of disaster, mangroves are directly accessible through experts' efforts to plant them.

By the spring of 2010, environmental consultants affiliated with Guyana's Ministry of Agriculture were responsible for implementing planting activities. All but one of the consultants was Guyanese, with prior experience working on statesponsored coastal environmental projects and, therefore, some experiential knowledge of mudbanks. With backgrounds in conservation and agroforestry, these consultants brought into focus mangroves' uncanniness as entities whose remedial properties and value lay in their situated vulnerability. Their efforts initially focused on planting black species, so as to not disrupt the shore's virtual monoculture. They sourced seedlings from the ministry's nursery, a decision they hoped would ensure sturdier roots than if seedlings were collected from wild forests. I walked with an environmental consultant to check on land that the team was preparing to sow. As we made our way, she explained: "We can declare the mangroves protected, but we can't just sit in sunshine. [What we do] isn't just about protecting mangroves: planting them . . . research is important . . ." The plots had their own disorienting presence, at once amplifying and scrambling the boundaries of the shoreline. But for seedlings to get their bearings, some concessions were required.

One of these concessions was the seawall. At a planting strategy meeting I attended, an engineer warned that on shore walks he had observed waves overtopping the seawall in places where it had never happened before. "Does this mean we should plant in front or behind the seawall?" he queried. An environmental consultant responded, suggesting that location was not the main issue in this instance. Mangroves' potential, in his account, lay in the availability of other kinds of plants to protect their stems and roots. He stressed that when dealing with mangroves the priority is to not discriminate, reiterating that mangroves can thrive near seawalls with mudbanks. Along these lines, he proposed that they also plant marine grasses (e.g., Spartina alterniaflora, also known as cord-grass) in what he called "acutely vulnerable" areas. He detailed distinctions between mangrove and marine grass species that were morphological, particularly the appearance and length of their root systems. The root systems also produced sensory capacities: "Once grasses are there, more whites [mangrove species] will know to come and be near the black mangrove." The consultant underscored this point by reminding the engineer of the multiple definitions of mangrove: "People often think 
that a mangrove is just a tree . . . but I mean a community of plants growing along the shore-a mangle of forests.”

There is very little fixed about taxonomy (Raffles 2011). The environmental consultant was not using the word mangle as a referent for a specific mangrove species, but was rather describing communities of plants with the potential to be domesticated as wave buffers. His distinction underscores a fundamental point of climate adaptation. The ineluctable blend of nature and technology in the practice of sea defense challenges the idea that climate adaptation is a mere effect of human science and its taxonomies. More than managed sites of biodiversity, these forests have lives that often push back and reorient algorithms of sea defense. In these forests, encounters unfold, and projects rise and fall.

Planting took place by trial and error. Dozens of volunteers helped the environmental consultants fill plastic bags with mud and seeds. They transported the bags to the shore at low tide and used wooden planks to transverse the muddy shores on their knees. They clawed through the mud to create crevices for the seedlings, alternating between bags filled with mangrove and grass seedlings. In some locations, the environmental consultants conceded that this technique might not be enough and so built fences to help stabilize seedlings' roots. After one season, they experienced some success, but still lost more than twenty thousand mangrove seedlings. Determined not to give in to the sea, the engineers prescribed that subsequent planting sessions would involve storing mangrove seedlings in the cracks of seawalls to help acclimate them to the shore before planting. In other cases, the environmental consultants outsourced nursery production to people who lived near forests, paying them to grow mangroves and to plant them only after they had matured.

In his analysis of mangroves and climate adaptation in Suriname, Ravic Nijbroek $(2014,534)$ argues that planting is a "situated environmental science." Based on historical field observations, experts have employed mudbank-migration models to justify planting and, at the same time, to acknowledge that mangroves are always already susceptible to so-called maladaptation. In both Guyana and Suriname, mangroves extend influence far enough and long enough to accommodate speculations about the terms of "collective empiricism" (Daston and Lunbeck 2011, 7; see also West 2008). Ultimately, the GMRP relied on planting procedures its participants knew were more than likely untenable as tides rose, but they did so in an attempt to increase forest populations in the present. One environmental consultant I interviewed spoke unselfconsciously about this paradox. She explained that the GMRP was establishing a new framework in "Guy- 
anese forestry," a framework in contrast to what she interpreted as the Global Climate Change Alliance's reductionist idea of mangrove nurseries. "The lady who did [the initial policy brief], her expertise was in mangrove nurseries in the Asian context, so it didn't have any of our specifics. A nursery is a nursery? No. But the mangrove protocol we now have talks about erosion. It's filled with stuff our engineers think blocks mangroves, those unknown processes [like sling-mud], you know. . . . With this [the GMRP], we have had to become a slew of local forest experts."

Although she had experience rehabilitating sea-turtle habitats in northeastern Guyana, this consultant's time planting pushed her to think of mangroves in a new way. They proved to be not merely standing reserves, but tacit reminders to humans of the shore's insecurity. Her objections to the initial policy brief demonstrate that climate adaptation depends on experts recognizing that their models and realities may not always align. Based on her time with the GMRP, the consultant worried that this fact is not so obvious once expert knowledge about climate adaptation achieves closure.

The GMRP's planting activities can thus be understood as what anthropologists of science, following Michael Fischer (2009), call experimental systems, instruments and practices that shape expert understandings of nature and its mutability. Through planting activities, GMRP participants have learned to treat differences and fluctuations within plant communities as essential components of climate adaptation. As such, their doubts about the life spans of trees remain useful resources for thinking about empirical matters (Mathews 2014). Importantly, these doubts underscore divisions in labor. Engineers remain invested in shore walks, albeit with an emphasis on tracking erosion and forest stocks. Environmental consultants are primarily invested in planting and tracking forest succession. But in the context of the GMRP, they have also "become a slew of local forest experts," meaning that their putatively translocal expertise has absorbed and been transformed by a new set of experiences with forests.

\section{PUTTING THE CART BEFORE THE HORSE}

With planting underway, the environmental consultants were eager to recruit another group of experts, beekeepers, to further advance their adaptation work. The beekeepers were drawn into the GMRP because of the environmental consultants' belief that apiaries had the potential to increase mangrove populations. The environmental consultants interpreted beekeepers' practices as commensurate with theirs and with those of the engineers and Nicholas, since bee- 
keepers were intimately familiar with the dynamics of mangrove forests even if their attention was focused differently.

Yet the GMRP's turn to beekeepers serves as a reminder that different expert practices produce different realities (Mol 2002). The continual rediscovery of mangrove reality through different expert lenses and the subsequent adjustment of expert practices prove integral to the way in which GMRP participants perceive mangroves as vulnerable. For example, instead of interpreting the life span of mangroves as mainly contingent on mudbanks, the beekeepers prompted the GMRP to rethink mangroves' life cycles through pollination as well. Climate adaptation not only has a tendency to disorient expertise but also to invite its reinvention through appeals to still other ways of understanding living things. But as the ecology of experts becomes more and more complex, these ways of understanding can diverge rather than converge, creating tensions that undermine an allegedly collaborative and synthetic enterprise such as the GMRP. Beekeepers working on the coast rely on an indigenous species of stingless bees (Meliponinae) that relies on black mangrove trees for feeding and breeding grounds (Bradbear 2009). Due to their particular scent, nectar type, and color of flower, black mangroves contribute to what Guyanese beekeepers call "tar honey" pollination. Even though mangroves are optimal feeding grounds for bees, beekeepers have had uneven success in coastal forests due to urbanization. Consequently, many professional beekeepers now work in the interior Amazonian region consulting on microfinance programs, developing apiaries with river-based red mangroves.

The beekeepers' initial concern about the GMRP revolved around whether they would receive short-term compensation for moving from the interior back to the coast. They claimed that it would take months to adjust their bees to a new landscape. The transition period, they argued, was an intuitive matter as much as a technical one, a point that a well-seasoned beekeeper knows all too well. They also requested private land plots to accommodate their bees' four- to five-mile flight patterns. Yet environmental consultants turned a deaf ear to the beekeepers, encouraging them to provide more scientific evidence for their requests. Citing Nicholas's and the engineers' work with the SWAN model, the environmental consultants warned that even if land officials granted plots, they were not confident about where land would eventually erode. Ultimately, they asked beekeepers to adapt their methods to smaller areas in reserves. The boundaries the environmental consultants articulated and the exclusions that they performed simultaneously coordinated and undermined another community of ex- 
perts' sustained interest in mangroves. The environmental consultants' request reverberated well beyond the boundaries of the reserves.

The home of Edward, a beekeeper consulting with the GMRP, signaled the tensions underlying their relationship. Mechanical toy bees hung from ceilings, educational posters describing bee species lined walls, and honey extractors and frames were stacked on floors. Resembling a museum display, his home spoke of an unstinting devotion to the insect, distinct from the ordinary world in which he struggled to master his craft undisturbed. A few days after Edward met with consultants about land plots, he explained to me the apparent disjuncture between his practices and their request. "No bees, no trees. . . . They [the consultants] don't understand. . . . They are putting the cart before the horse." Edward suggested that the SWAN model itself was a contributing factor to the destruction of forests through its elevation of sedimentation and mudscapes over pollination. To further emphasize this point, he narrated the history of the arrival of Africanized bees (Apis mellifera) to the coastal mangrove apiaries. Within the first years of handling Africanized bees, Edward recounted that the majority of the stingless population collapsed. The introduction of a new species pushed beekeepers out of business because they did not know how to "smoke out" the bees' aggressive behavior. By the late 1980s, Edward and his colleagues had adapted to the new species, but it was already too late. Much of the standing mangrove forest where he had worked was gone. Edward explained: "By the time the mangroves were destroyed I really began to learn the bees' flight, how to read them. I could tell you if the rain was going to fall, how long, when the trees are blossoming. . . . If I visited my hive I saw them working. They sing and move to make it plain to me that mangroves are healthy despite whatever cycle of erosion.”

Edward regards his expertise as grounded in the entangled histories of bee, human, and plant kinetics that have contributed to climatological insecurities (Kosek 2010). He reframes a taken-for-granted assumption of the SWAN model, arguing that bees can aid mangroves even during mudbanks' microerosion cycles.

The expert focus on pollination created awareness among GMRP participants about subtle variations and temporalities in mangrove regeneration, disrupting certain assumptions on which the group relied. Pollination offered a new view toward the resurrection, not merely the transformation, of mangrove forests. At the same time, pollination is indifferent to the expert modes of organization, measurement, and observation that the GMRP envisions as crucial to mangroves' protection. Bees and mangroves do have a coevolutionary relationship 
with mudbanks. But bees have their own everyday lives of communication and occupation that has often simply ignored mangroves.

It is in such moments of divergence that it becomes unclear who is adapting to what and to whom. These entanglements have unsettling effects that disrupt domains of expertise within the GMRP. Climate adaptation, therefore, is rarely born out of convenience, but rather out of the necessity of recognizing the power of the world to challenge and reshape expert paradigms.

\section{CONCLUSION: Inverse Performativity}

Mangroves are good to think with, especially as to who or what should count as expert in the Anthropocene. They are the evidence GMRP participants use to issue warnings about sea-level rise. At the same time, mangroves participate in the material constitution of expert practices. While GMRP participants recognize mangroves' capacity for sea defense, mangroves challenge existing arrangements of human defense technologies like seawalls and groynes. In so doing, mangroves foster relations that blur boundaries between land and sea, animate and inanimate, nature and society in manners rarely anticipated by technoscientific bureaucracies. Sometimes glossed as simple wave buffers, mangroves are often seen in pragmatic terms of their technological value. But as I have shown, mangroves - as seed pods, root systems, and objects of pollination-are also material forces that inform and challenge expert practices in diverse ways. They coordinate activities between GMRP participant groups while also placing these groups in tension with one another, as each seeks to advance its own ideas for mangrove protection, management, or change.

There are a number of different theoretical approaches for framing the demands on and for expertise that I have laid out here. Throughout this article, I have suggested that one approach is to treat climate adaptation as a specific case of a move away from representationalist approaches to performativity (Mitchell 2002; Pickering 1995). Climate adaptation, on this view, takes its cues from Karen Barad's (2003) philosophy of posthumanist performativity. Barad emphasizes the relational ontology that informs the production of technoscientific expertise, particularly with regard to the apparatuses experts use to make observations. Apparatuses are not "static arrangements" (Barad 2003, 816) but sets of practices that enact boundaries, allowing experts to see certain things in the world and not others. In other words, there is no inherent separation between the observer and the observed. Apparatuses are a property of the phenomena observed; they create obligations and demand particular kinds of responses from 
experts. For Barad, technoscientific facts are not a given, and neither are the relationships experts cultivate with apparatuses.

A recursive relationship between apparatuses and the realities GMRP participants attempt to model is also at play in their work with mangroves. In the first instance, as I have shown, they make observational assessments about the kinds of vulnerability that exist in forests, such that their own models come into question. Second, these assessments provoke participants to collaborate across divisions of specialization, labor, and socio-professional affiliation to respond to mangrove loss. Third, these efforts at collaboration yield mixed, uncertain, and sometimes contentious results. This relational ontology is emblematic of climateadaptation policy's operative logics, or what I would call inverse performativity. It is a process whereby an unruly world forces one expert group to seek help from others, building a new ecology of expertise to adapt to a changing climate. ${ }^{8}$

Thinking in terms of inverse performativity helps to clarify not only how climatological expertise is produced but also how it materializes. Ethnographic studies of climate change have taken up this point to demonstrate the role that model outputs play in the formation of expert cultures (Lahsen 2005; Taddei 2012). Uncertainty emerges as a central theme, with scholars detailing discourses about model accuracy, visual styles of models, and the socio-political stakes of modeling. But as I have suggested, settings like the GMRP also force experts to speculate about the validity of their own and others' models and the importance of activities besides modeling (like shore walks and plantings). The idea that climate adaptation depends solely on modeling operations is not self-evident. Instead, the efficacy of this claim is continuously remade, as experts learn to engage vulnerable environments. And while they learn, the nonhuman world continues to wield a considerable force that pays little heed to experts' ideas and activities.

Many places in which experts implement climate-adaptation policies are more than vulnerable; they are experiencing radical biodiversity loss. This distinction is important because it reveals the differential, yet indeterminate material conditions that shape the formation of climate-adaptation policies. It reminds us why models matter in climate adaptation: they can pattern the chances of certain humans and nonhumans to survive the next disaster. Sometimes models can shore up relationships of accountability (Scott 2014). To this extent, anthropological studies of climate adaptation require ethnographic specificity about knowledge production and the epistemic politics that make adaptation imaginable. In particular, climate adaptation raises questions about the resilience of local and national 
expertise and the influence of transnational climate institutions in disavowing that expertise. ${ }^{9}$ Climate adaptation can make the expert seem rather vulnerable. In what are often concerning or even desperate conditions, other cultures of expertise and the nonhuman world are not always on the expert's side.

The GMRP participants' first-order analyses of mudbanks and mangroves aptly demonstrate these concerns. From tacit to explicit claims about the sociality of mangroves, the participants recognize that climate adaptation constitutes a moving target. The turn to climate adaptation implicates them in broader conversations about modernization as a relic of the Anthropocene. These conversations unfold within a national context in which sea defense has been continuously made over by external agents - be these mudbanks, colonizers, donor organizations, or the sea. To be sure, these conversations have broader implications for environmental justice, particularly as disasters loom that blur contestations over social and environmental forms of citizenship (Vaughn 2012). Inverse performativity thus occurs not only within rarified domains of government science but also across other sectors of society, as the experiences of beekeepers with the GMRP indicate. The inverse performativity of the Anthropocene shapes expert understandings of biopolitical possibility in geological time. How climate adaptation develops in concert with genealogies of power, geopolitics, and narrative strategies about nature lies at the very heart of these understandings. Yet it is also incumbent on us to consider what constitutes expertise and how this question materializes across a vulnerable planet.

\begin{abstract}
This article details the epistemic politics that shape the climate adaptation of sea defense in Guyana. Rethinking the material arrangements of expertise in the Anthropocene, I track the work of a group of technoscientific experts participating in the Guyana Mangrove Restoration Project (GMRP). In an attempt to redesign sea defense around mangrove ecosystems, GMRP participants recognize that climate adaptation is not solely dependent on their well-intentioned efforts. As research objects, mangroves are not only forms of evidence but also tools that guide expert action and distinctions in day-to-day labor. Moreover, mangroves draw out the explicit contingencies of modeling, placing expert groups in tension with one another as each seeks to advance their own ideas for mangrove protection, management, or change. I show that this relational ontology is emblematic of climate-adaptation policy's broader operative logics, or what I call inverse performativity. This is a process whereby an unruly world forces one expert group to seek help from others, building a new ecology of expertise to adapt to a changing climate. Impermanent and wondrous, mangroves urge us to think more creatively about vulnerability to climate change and
\end{abstract}


the kinds of practices that inspire knowledge about it. [expertise; vulnerability; climate adaptation; geological imaginaries; mangroves]

\section{NOTES}

Acknowledgments I am indebted to all those who worked for the GMRP and welcomed me into their professional and personal lives. My explorations would not have been possible without their interest and, most of all, their patience. I am grateful to Andy Graan, Elina Hartikainen, Karl Swinehart, Joe Masco, David Bond, Ben Orlove, Ram Natarajan, and Don Moore for their sharp readings of various drafts. I would like to give special thanks to Jake Kosek for challenges that pushed me to think critically about the many forms expertise and vulnerability take. This article also benefited from engagements at the MIT-Harvard Workshop for the History of Environment, Agriculture, Technology, and Science, the Ethnography and Social Theory Colloquium in the Department of Anthropology at Yale University, and the Environmental Studies Workshop at the University of Chicago. The Cultural Anthropology editorial collective and anonymous reviewers provided invaluable feedback that made this article possible. I especially thank Dominic Boyer for his thoughtful suggestions and encouragement. Finally, research for this article was supported by the Mellon Mays-Social Science Research Council grant initiatives and the American Council of Learned Societies.

1. I refer to many of my informants by pseudonyms to protect their privacy.

2. Archaeologists and historical anthropologists debate whether the early sugar industry's grid had any overlap with flood structures built by Arawak communities in the Guianas' upriver region (Whitehead, Heckenberger, and Simon 2010).

3. Historians attribute a so-called technical crisis during this period to the majority AfroGuyanese socialist government's doctrine of party paramountcy. This doctrine ensured that high-level government positions were filled by those supporting Guyana's vanguard party, which espoused a Julius Nyerere-inspired Black Nationalist populism.

4. The association between engineering and modernization in Guyana, as in many other parts of the world, cannot be overstated. The ethnographic record is ripe with examples of plantation infrastructures as components of a total social institution that shape, among other things, racial-political identities. In the case of state bureaucracy, many speculate that the socialist government prioritized funding for sea defense over irrigation and drainage because Indo-Guyanese were the majority ethnic labor pool in the agriculture sector. The divestment ignited racial divisions within the engineering public sector. Since, engineers have referred to the Ministry of Public Works as a stereotypically "Black agency," and the Ministry of Agriculture as a stereotypically "Indian agency." In practice, however, these stereotypes are routinely ignored or circumvented for technical and political reasons (see Williams 1991).

5. This critique of the state's technical crisis was reversed with liberalization when a majority Indo-Guyanese government came into power and was understood by many to espouse the "Hinduization" of state bureaucracy.

6. The LCDS has involved a shift in the state's focus from agriculture toward green economies that purportedly rely on Amerindian forms of expertise (e.g., investments in microcapital grants in carbon markets and tourism in the interior Amazonian region). This means that GMRP participants' time spent "shadowboxing in the mangrove" (Price and Price 1997) reshapes links not only between expertise and identity but also with landscapes vulnerable to climate change.

7. GMRP participants' efforts to act in the interim resemble what Lauren Berlant (2011, 24) calls "crisis ordinariness," or adjustments to living with unpredictability in the everyday.

8. It is with this point about collaboration between expert groups that I extend Karen Barad's notion of a posthumanist performativity. As the GMRP's work suggests, not every expert claims or desires to be a posthumanist in the same way; philosophies of posthumanism create boundaries as much as they erase them. 
9. I am not advocating salvage ethnography. Instead, I focus on the material-representational resources through which claims to expertise about climate adaptation are produced and circulated across scales. It is a focus related to Manuel De Landa's (2000) method of seeking to sort out the "genesis of form" between natural histories and knowledge practices.

\section{REFERENCES}

Appadurai, Arjun

2015 Banking on Words: The Failure of Language in the Age of Derivative Finance. Chicago: University of Chicago Press.

Barad, Karen

2003 "Posthumanist Performativity: Toward an Understanding of How Matter Comes to Matter." Signs 28, no. 3: 801-31. https://doi.org/10.1086/345321.

Barnes, Jessica

2016 "Uncertainty in the Signal: Modeling Egypt's Water Signals." Journal of the Royal Anthropological Institute 22, no. S1: 46-66. https://doi.org/10.1111/14679655.12393.

Battacharya, Rahul

2011 The Sly Company of People Who Care. New York: Macmillan.

Berlant, Lauren

2011 Cruel Optimism. Durham, N.C.: Duke University Press.

Bijker, Wieber E.

2007 “Dikes and Dams, Thick with Politics." Isis 98, no. 1: 109-123. https://doi.org/ $10.1086 / 512835$.

Bourdieu, Pierre

1991 Language and Symbolic Power. Translated by John B. Thompson. Cambridge, Mass.: Harvard University Press.

Boyer, Dominic

2008 “Thinking through the Anthropology of Experts." Anthropology in Action 15, no. 2: 38-46. https://doi.org/10.3167/aia.2008.150204.

Bradbear, Nicola

2009 "Bees and Their Role in Forest Livelihoods: A Guide to the Services Provided by Bees and the Sustainable Harvesting, Processing, and Marketing of Their Products." Nonwood Forest Products, no. 19. Rome: Food and Agriculture Organization. http://www.fao.org/docrep/012/i0842e/i0842e00.htm.

Braun, Bruce P.

2014 “A New Urban Dispostif? Governing Life in the Age of Climate Change." Environment and Planning D 32, no. 1: 49-64. https://doi.org/10.1068/d4313.

Callon, Michel, ed.

1998 Law of the Markets. Malden, Mass.: Blackwell.

Carr, E. Summerson

2010 "Enactments of Expertise." Annual Review of Anthropology 39: 17-32. https://

Case, Gerald O. doi.org/10.1146/annurev.anthro.012809.104948.

1920 Coast Erosion Protection Works on the Case System in British Guiana. New York: Tidal Engineering Corporation.

Chakrabarty, Dipesh

2009 "The Climate of History: Four Theses." Critical Inquiry 35, no. 2: 197-222. https://doi.org/10.1086/596640.

Crate, Susan A., and Mark Nuttall, eds.

2016 Anthropology and Climate Change: From Actions to Transformations. 2nd edition. New York: Routledge.

Cruikshank, Julie

2005 Do Glaciers Listen? Local Knowledge, Colonial Encounters, and Social Imagination. Vancouver: University of British Columbia Press. 
Dalrymple, Omatoyo Kofi, and Roger S. Pulwarty

2006 "Sea-level Rise Implications for the Coast of Guyana: Sea Walls and Muddy Coasts." Paper presented at the Fourth Latin American and Caribbean Conference for Engineering and Technology, Mayagüez, Puerto Rico, June 2123.

Daston, Lorraine, and Elizabeth Lunbeck

2011 "Introduction: Observing Observed." In Histories of Scientific Observation, edited by Lorraine and Elizabeth Lunbeck, 1-9. Chicago: University of Chicago Press.

De Landa, Manuel

2000 "Deleuze, Diagrams, and the Genesis of Form." Amerikastudien/American Studies 45, no. 1: 33-41. https://www.jstor.org/stable/41157534.

Delft Hydraulics Laboratories

1962 "Demerara Coastal Investigation: Report on Siltation of Demerara Bar Channel and Coastal Erosion in British Guiana.” Delft, Netherlands: Delft Hydraulics Laboratory.

du Gay, Paul

2010 "Performativities: Butler, Callon, and the Moment of Theory." Journal of Cultural

Economy 3, no. 2: 171-79. https://doi.org/10.1080/17530350.2010.494120.

Fischer, Michael M. J.

2009 Anthropological Futures. Durham, N.C.: Duke University Press.

Government of Guyana

2010 “Transforming Guyana's Economy while Combating Climate Change: A LowCarbon Development Strategy." Georgetown, Guyana: Office of the President.

Hastrup, Kirsten

2013 “Anticipating Nature: The Productive Uncertainty of Climate Models." In The Social Life of Climate Change Models: Anticipating Nature, edited by Kristen Hastrup

Helmreich, Stefan and Martin Skrydstrup, 1-29. New York: Routledge.

2011 “Nature/Culture/Seawater." American Anthropologist 113, no. 1: 132-44. https: / / doi.org/10.1111/j.1548-1433.2010.01311.x.

Kirby, Andrew, Peter Meesen, and Henk Ognik

2006 "Engineering Assessment of 2006 Floods." Report for the Government of Guyana. Georgetown, Guyana: United Nations Development Program.

Kohn, Eduardo

2015 “Anthropology of Ontologies.” Annual Review of Anthropology 44: 311-27. https://doi.org/10.1146/annurev-anthro-102214-014127.

Kosek, Jake

2010 "Ecologies of Empire: On the New Uses of the Honeybee." Cultural Anthropology 25, no. 4: 650-78. https://doi.org/10.1111/j.1548-1360.2010.01073.x.

Lahsen, Myanna

2005 "Seductive Simulations? Uncertainty Distribution around Climate Models." Social Studies of Science 35, no. 6: 895-922. https://doi.org/10.1177/ 0306312705053049 .

Latour, Bruno

2014 "Agency at the Time of the Anthropocene." New Literary History 45, no. 1: 118. https://doi.org/10.1353/nlh.2014.0003.

Ledden, Mathijs van, Geoffrey Vaughn, Joost Lansen, Frank Wiersma, and Mewburn

Amsterdam

2009 "Extreme Wave Event along the Guyana Coastline in October 2005." Continental

Shelf Research 29, no. 1: 352-61. https://doi.org/10.1016/j.csr.2008.03.010.

Lee, Benjamin, and Edward LiPuma

2002 "Cultures of Circulation: The Imaginations of Modernity." Public Culture 14, no. 1: 191-213. https://doi.org/10.1215/08992363-14-1-191. 
Lipset, David

2013 "The New State of Nature: Rising Sea Levels, Climate Justice, and Communitybased Adaptation in Papua New Guinea (2003-2011)." Conservation and Society 11, no. 2: 144-58. https://doi.org/10.4103/0972-4923.115726.

MacKenzie, Donald

2006 An Engine, Not a Camera: How Financial Models Shape Markets. Cambridge, Mass.: MIT Press.

MacKenzie, Donald, Fabian Muniesa, and Lucia Siu

2007 "Introduction." In Do Economists Make Markets? On the Performativity of Economics, 1-19. Princeton, N.J.: Princeton University Press.

Mathews, Andrew S.

2014 "Scandals, Audits, and Fictions: Linking Climate Change to Mexican Forests." Social Studies of Science 44, no. 1: 82-108. https://doi.org/10.1177/ 0306312713490330.

McLean, Stuart

2011 "Black Goo: Forceful Encounters with Matter in Europe's Muddy Margins." Cultural Anthropology 26, no. 4: 589-619. https://doi.org/10.1111/j.15481360.2011.01113.x.

Mitchell, Timothy

2002 Rule of Experts: Egypt, Techno-Politics, Modernity. Berkeley: University of California Press.

Mol, Annemarie

2002 The Body Multiple: Ontology in Medical Practice. Durham, N.C: Duke University Press.

Myers, Natasha

2015 "Conversations on Plant Sensing: Notes from the Field." NatureCulture, no. 3: 35-66. http: / / natureculture.sakura.ne.jp/03-acting-with-non-human-entities.

Nijbroek, Ravic

2014 "Mangroves, Mudbanks, and Seawalls: Whose Environmental Knowledge Counts when Adapting to Sea Level Rise in Suriname?" Journal of Political Ecology 21: 533-50. http://jpe.library.arizona.edu/Volume21/Volume_21.html.

Ogden, Laura A.

2011 Swamplife: People, Gators, and Mangroves Entangled in the Everglades. Minneapolis: University of Minnesota Press.

Orlove, Benjamin

2009 "The Past, the Present, and Some Possible Futures of Adaptation." In Adaptation to Climate Change: Thresholds, Values, Governance, edited by Neil Adger, Irene Lorenzoni, and Karen O’Brien, 131-63. New York: Cambridge University Press.

Petryna, Adriana

2015 "What is a Horizon? Navigating Thresholds in Climate Change Uncertainty." In Modes of Uncertainty: Anthropological Cases, edited by Limor Samimian-Darash and

Pickering, Andrew Paul Rabinow, 147-64. Chicago: University of Chicago Press.

1995 The Mangle of Practice: Time, Agency, and Science. Chicago: University of Chicago Press.

Price, Richard, and Sally Price

1997 "Shadowboxing in the Mangrove." Cultural Anthropology 12, no. 1: 3-36. https://

Raffles, Hugh doi.org/10.1525/can.1997.12.1.3.

2011 Insectopedia. New York: Vintage.

Redfield, Peter

2000 Space in the Tropics: From Convicts to Rockets in French Guiana. Berkeley: University of California Press. 
Rodney, Walter

1981 A History of the Guyanese Working People, 1881-1905. Baltimore, Md.: Johns Hopkins University Press.

Rose, Euclid A.

2002 Dependency and Socialism in the Modern Caribbean: Superpower Intervention in Guyana, Jamaica, and Grenada, 1970-1985. Lanham, Md.: Lexington Books.

Schomburgk, Richard

1922 Travels in British Guiana, 1840-1844. Edited by Walter E. Roth. Georgetown,

Scott, David British Guiana: Daily Chronicle.

2014 Omens of Adversity: Tragedy, Time, Memory, Justice. Durham, N.C.: Duke University Press.

Stengers, Isabelle

2000 The Invention of Modern Science. Translated by Daniel W. Smith. Minneapolis: University of Minnesota Press. Originally published in 1993.

Stoler, Ann Laura

2008 "Epistemic Politics: Ontologies of Colonial Common Sense." Philosophical Forum 39, no. 3: 349-61. https://doi.org/10.1111/j.1467-9191.2008.00303.x.

Taddei, Renzo

2012 "The Politics of Uncertainty and the Fate of Forecasters." Ethics, Policy, and Environment 15, no. 2: 252-67. https://doi.org/10.1080/21550085.2012. 685603.

Tsing, Anna Lowenhaupt

2015 The Mushroom at the End of the World: On the Possibility of Life in Capitalist Ruins. Princeton, N.J.: Princeton University Press.

Vaughn, Sarah E.

2012 "Reconstructing the Citizen: Disaster, Citizenship, and Expertise in Racial Guyana.” Critique of Anthropology 32, no. 4: 359-87. https://doi.org/10.1177/ $0308275 \times 12467718$.

West, Paige

2008 "Tourism as Science and Science as Tourism: Environment, Society, Self, and Other in Papua New Guinea." Current Anthropology 49, no. 4: 597-626. https:// doi.org/10.1086/586737.

Whitehead, Neil, Michael Heckenberger, and George Simon

2010 "Materializing the Past among the Lokono (Arawak) of the Berbice River, Guyana." Anthropológica, no. 114: 87-127.

Whitington, Jerome

2016 "Modernist Infrastructure and the Vital Systems Security of Water: Singapore's Pluripotent Climate Futures.” Public Culture 28, no. 2: 415-41. https://doi.org/

Williams, Brackette F. 10.1215/08992363-3427511.

1991 Stains on My Name, War in My Veins: Guyana and the Politics of Cultural Struggle. Durham, N.C.: Duke University Press.

Winter, Alexander

1883 “Our Muddy Shores." Timehri 11: 1-11.

Winterwerp, J. C., R. F. de Graaff, J. Groeneweg, and A. P. Luijendijk

2007 "Modeling of Wave Damping at Guyana Mud Coast." Coastal Engineering 54, no. Yusoff, Kathryn 3: 249-61. https://doi.org/10.1016/j.coastaleng.2006.08.012.

2013 "Geologic Life: Prehistory, Climate, Futures in the Anthropocene." Environment and Planning D 31, no. 5: 79-95. https://doi.org/10.1068/d11512. 